\title{
NOWE STANOWISKO SOPLÓWKI BUKOWEJ HERICIUM CORALLOIDES (SCOP.) PERS. W WIELKOPOLSCE
}

\author{
ANNA KUJAWA, JUDYTA KONIK \\ Instytut Środowiska Rolniczego i Leśnego PAN, \\ ul. Bukowska 19, 60-809 Poznań \\ e-mail: zardaria@wp.pl
}

\begin{abstract}
The paper presents a new locality of the protected fungus Hericium coralloides located in a manorial park in Turew. Nine basiodiocarps grew on a fragment of trunk of Ulmus sp. lying at the alley. The described locality is the fourth known in Wielkopolska region.
\end{abstract}

Keywords: fungi, protected species, manorial park, agricultural landscape, Poland

\section{WSTĘP}

Soplówka bukowa Hericium coralloides (Scop.) Pers. podlega w Polsce częściowej ochronie gatunkowej (Rozporządzenie... 2014). Uznana jest za gatunek narażony na wymarcie (kategoria V) (Wojewoda, Lawrynowicz 2006). Jest grzybem saprotroficznym rozwijającym się na martwym drewnie drzew liściastych, przede wszystkim buka Fagus sylvatica. Rzadziej wyrasta na innych drzewach liściastych: osikach Populus tremula, brzozach Betula spp., wiązach Ulmus spp., jesionach Fraxinus spp., dębach Quercus spp., morwie Morus spp. i jabłoni Malus spp. (Bernicchia, Padovan 1997; Pegler i in. 1997; Bernicchia, Gorjón 2010). Związana jest z lasami o charakterze naturalnym, z zamierającymi, starymi, sędziwymi drzewami i martwym drewnem pozostawionym na dnie lasu do samoczynnego rozkładu (Boody i in. 2001). Podstawowym zagrożeniem dla tego grzyba jest mała powierzchnia takich lasów w Polsce i ich rozdrobnienie, powodujące znaczącą izolację miejsc dogodnych do jego rozwoju (Domian 2015). W Polsce soplówkę bukową stwierdzono na ponad 50 stanowiskach (Wojewoda 2003; Kujawa 2016). W Wielkopolsce - przyjmując granice według opracowania Lisiewskiej i Madei (2003) - znana jest z trzech stanowisk:

1. Rezerwatu „Buki nad Jeziorem Lutomskim” i jego bezpośredniego sąsiedztwa (gm. Sieraków; Lisiewska, Madeja 2003 - nazwa rezerwatu „Buki Lutomskie", Bujakiewicz, Springer 2009).

2. Rezerwatu „Jezioro Trzebidzkie” (gm. Przemęt; Brzeg i in. 2005). 
3. Między Skoroszowem a Lasowicami (Borowina) k. Milicza (gm. Milicz; Kujawa 2005; Kujawa, Gierczyk 2010).

\section{MATERIAŁ I METODY}

Nowe stanowisko soplówki bukowej w Wielkopolsce stwierdzono podczas kontroli terenowej drzew uszkodzonych w następstwie wichury w parku pałacowym w Turwi, w Parku Krajobrazowym im. gen. Dezyderego Chłapowskiego. Owocniki udokumentowano fotograficznie.

\section{OPIS STANOWISKA}

Owocniki soplówki bukowej znaleziono 13 października 2016 r. w zabytkowym parku pałacowym w Turwi (gm. Kościan, pow. kościański, ATPOL Db 48-00). Na pozostawionym po uprzątaniu wiatrołomów wałku wiązowym wyrastało dziewięć owocników na powierzchni cięcia oraz na bokach (ryc. 1, 2). Stanowisko znajduje się przy alei parkowej po zachodniej stronie pałacu, w pobliżu

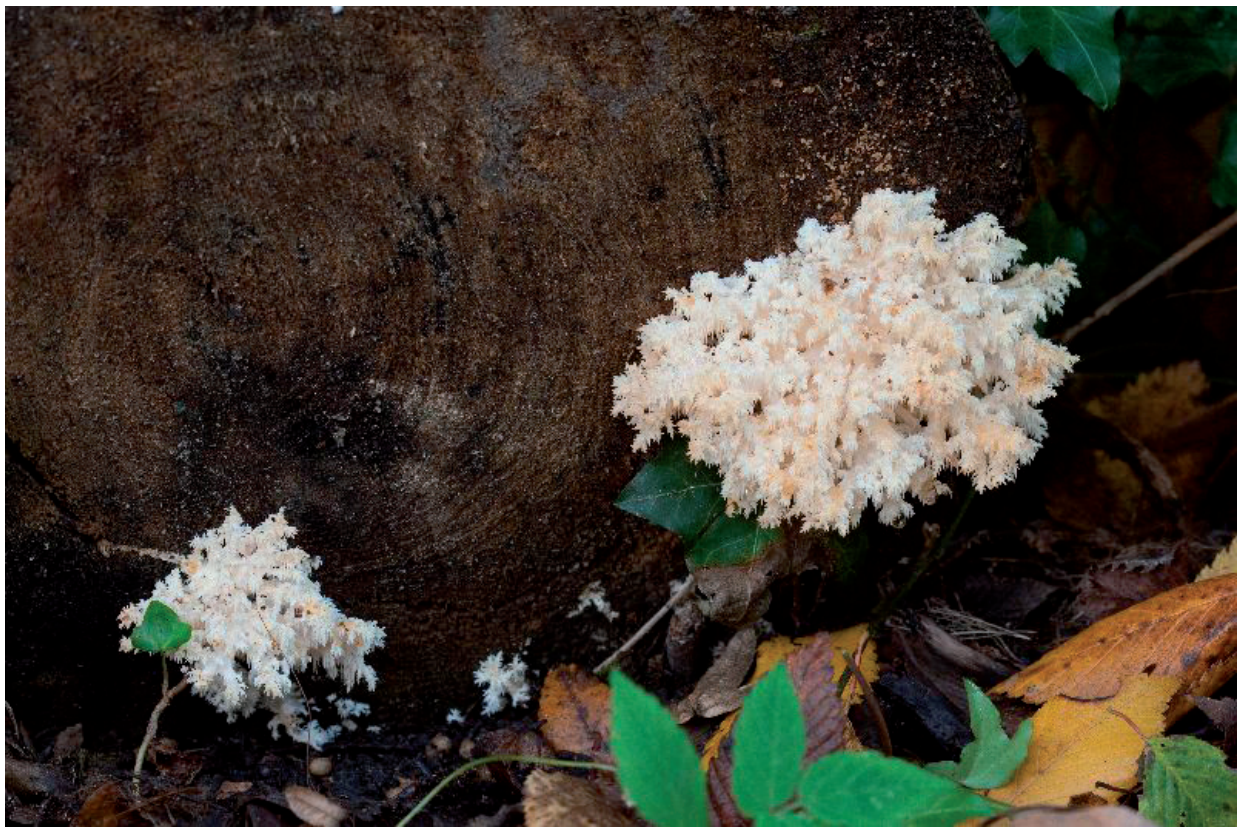

Ryc. 1. Owocniki Hericium coralloides wyrastające na powierzchni cięcia na drewnie wiązu. Fot. K. Kujawa

Fig. 1. Hericium coralloides fruit-bodies growing on cutting surface of elm wood piece.

Phot. K. Kujawa 


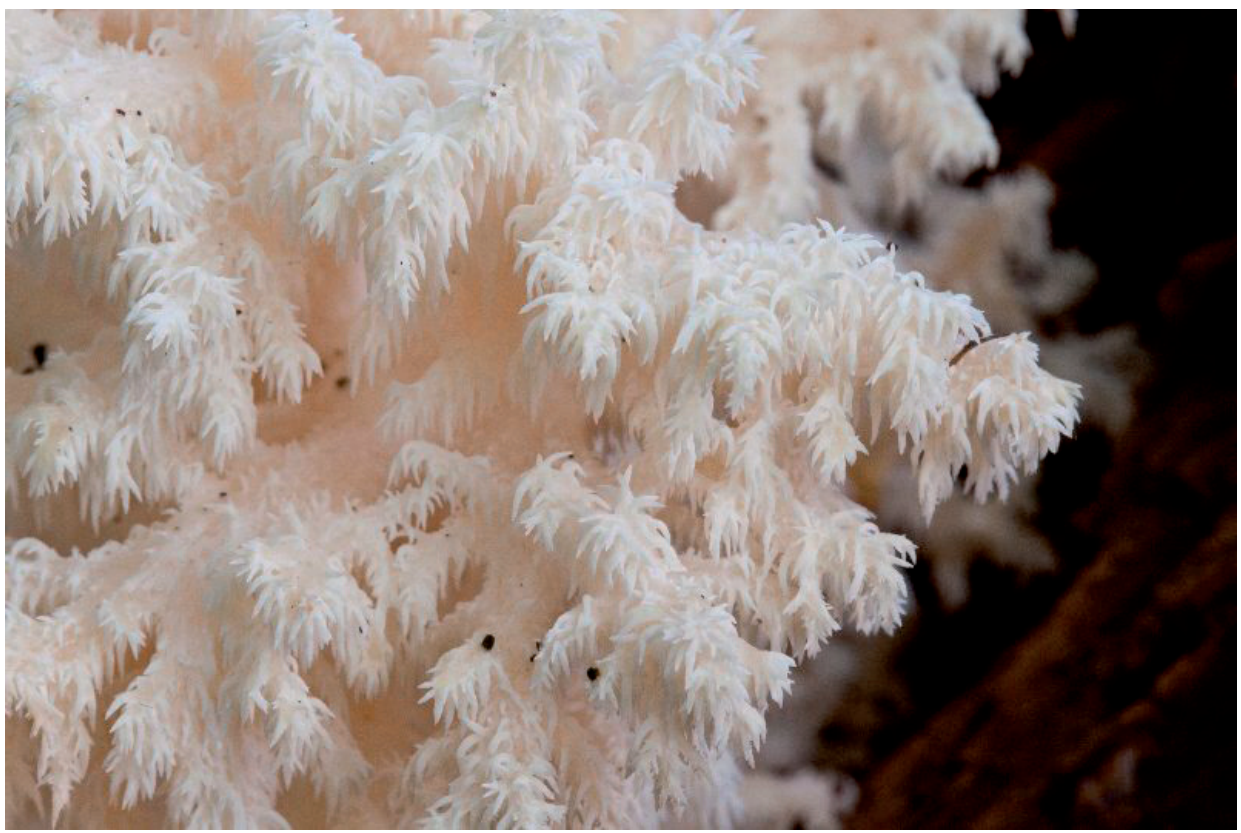

Ryc. 2. Fragment owocnika Hericium coralloides wyrastającego na powierzchni cięcia na drewnie wiązu. Fot. K. Kujawa

Fig. 2. A part of Hericium coralloides fruit-body growing on cutting surface of elm wood piece. Phot. K. Kujawa

stojącego złomu wiązu Ulmus laevis o pomnikowych rozmiarach. Fragmenty pnia i konarów pozostawione są do samoistnego rozpadu.

\section{PODSUMOWANIE}

Pierwsze stwierdzenie soplówki bukowej na terenie zabytkowego Parku Krajobrazowego im. gen. Dezyderego Chłapowskiego, pełniącego rolę wyspy leśnej w krajobrazie rolniczym i będącego ostoją dla wielu rzadkich i chronionych gatunków grzybów (Bujakiewicz, Kujawa 2000), potwierdza istotną rolę, jaką spełniają tego typu środowiska w wylesionym krajobrazie rolniczym.

\section{LITERATURA}

Bernicchia A., Gorjón S. P. (2010): Corticiaceae s.l. Fungi Europaei, 12. Ss. 1007. Ed. Candusso. Italia.

Bernicchia A., Padovan F. (1997): Preliminary distributional data on Hericiaceae (Basidiomycetes) in Italy. Bocconea, 5: 853-859. 
Boddy L., Crockatt M. E., Ainsworth A. M. (2011): Ecology of Hericium cirrhatum, H. coralloides and H. erinaceus in the UK. Fungal Ecol., 4: 163-173.

Brzeg A., Gąbka M., Nagengast B. (2005): Szata roślinna rezerwatu przyrody „Jezioro Trzebidzkie". Biul. Park. Krajobraz. Wielkopolski, 11(13): 153-196.

Bujakiewicz A., Kujawa A. (2000): Macrofungi of manorial park in Turew near Poznań. Acta Mycol., 35(2): 183-195.

Bujakiewicz A., Springer N. (2009): Udział macromycetes w lasach łęgowych rezerwatu „Buki nad Jeziorem Lutomskim" (nadleśnictwo Sieraków). Bad. Fizjogr. nad Polską Zach., B, 58: 171-204.

Domian G. (2015): Soplówka bukowa i soplówka jeżowata w Puszczy Bukowej koło Szczecina - wstępna ocena trwałości stanowisk. Stud. i Mat. CEPL w Rogowie, R. 17, 44(3): 71-83.

Kujawa A. (2005): Rejestr gatunków grzybów chronionych i zagrożonych - nowa forma gromadzenia danych mikologicznych pochodzących od amatorów. Podsumowanie roku 2005. Przegl. Przyr., 16(3-4): 17-52.

Kujawa A. (2016): Grzyby makroskopijne Polski w literaturze mykologicznej. [W:] Snowarski M. Atlas grzybów Polski. http://www.grzyby.pl/grzyby-makroskopijne-Polski-w-literaturzemikologicznej.htm (dostęp: 27.01.2017).

Kujawa A., Gierczyk B. (2010): Rejestr gatunków grzybów chronionych i zagrożonych w Polsce. Część III. Wykaz gatunków przyjętych do rejestru w roku 2007. Przegl. Przyr., 21(1): 8-53.

Lisiewska M., Madeja J. (2003): Rozmieszczenie ściśle chronionych gatunków grzybów w Wielkopolsce. Bad. Fizjogr. nad Polską Zach., B, 62: 7-25.

Pegler D. N., Roberts P. J., Spooner B. M. (1997): British Cantharelles and tooth-fungi. Ss. 114. Royal Botanical Garden. Kew.

Rozporządzenie Ministra Środowiska z dnia 9 października 2014 r. w sprawie ochrony gatunkowej grzybów. Dz.U, poz. 1408

Wojewoda W. (2003): Checklist of Polish larger Basidiomycetes. Ss. 812. W. Szafer Inst. of Bot., Pol. Acad. of Sci. Kraków.

Wojewoda W., Ławrynowicz M. (2006): Red list of the macrofungi in Poland. [W:] Mirek Z., Zarzycki K., Wojewoda W., Szeląg Z. (red.). Red list of plants and fungi in Poland: 54-70. W. Szafer Inst. of Bot., Pol. Acad. of Sci. Kraków.

\section{NEW LOCALITY OF HERICIUM CORALLOIDES (SCOP.) PERS. IN THE WIELKOPOLSKA REGION}

\section{Summary}

Hericium coralloides is considered to be endangered (V category) and is protected by law in Poland. With respect to the Wielkopolska region, it has been found in three localities, two of which are located in nature reserves. The new locality was found on 13 October 2015 in a manorial park in the village of Turew, located in the General Dezydery Chłapowski Landscape Park. The most important threat to the species is a loss of favorable habitats, i.e. forests of natural character, rich in old trees and dead wood. The new locality of Hericium coralloides in Turew confirms the important role of rural parks (an example of wood island), for supporting high level of biodiversity. 